\title{
Women's Employment and Fertility: A Welfare Regime Paradox
}

Liana Christin Landivar

U.S. Department of Labor*

liana.c.landivar@gmail.com

Carter T. Butts

Department of Sociology and Institute for Mathematical Behavioral Sciences

University of California, Irvine

buttsc@uci.edu

\begin{abstract}
In this article we methodologically assess the paradox posited by other researchers of fertility: namely, why fertility is so much lower in the familialistic countries of Southern and Eastern Europe. We examine the relationship between individual attributes, aggregate female labor force participation, child care enrollment, family leave, and individual fertility in twenty developed countries using a hierarchical Bayesian model. Our results indicate that women's full-time employment and country-level employment rates decrease expected fertility in contrast to recent research which shows a reversal in the negative association between total fertility rates and female labor force participation during the 1980s. However, the positive association between child care enrollment and fertility indicates that child care services might mitigate some of the decline in fertility, possibly by reducing labor force exit among women with young children.

Key words: fertility; gender; women's employment; child care; family policy; welfare states

*The authors completed this research while at the University of California, Irvine. Any views expressed herein are those of the authors and not necessarily those of the U.S. government. The authors would like to acknowledge the thoughtful comments and guidance provided by Judith Treas, Joy Pixley, and Wang Feng. We are also grateful for the helpful suggestions provided by several anonymous reviewers.
\end{abstract}

\section{Published in Social Science Research:}

Hilgeman, Christin and Carter T. Butts. 2009. “Women's Employment and Fertility: A Welfare

Regime Paradox." Social Science Research 38(1): 103-117.

https://doi.org/10.1016/j.ssresearch.2008.08.005 


\section{Women's Employment and Fertility: A Welfare Regime Paradox}

In light of the significant decline in fertility within many countries to below-replacement levels in recent decades, researchers have noted that countries with higher levels of women's labor force participation also retain higher total fertility rates (Brewster and Rindfuss 2000; Rindfuss et al. 2003; Sleebos 2003; Esping-Andersen 1999). This seems counter-intuitive given the robust finding in the literature that women who are employed tend to have lower fertility than those who are not employed (Budig 2003; Hakim 2003; Lesthaeghe 1995; Sundtröm 2000). These results have been reconciled by assuming that women in countries where more women are employed have been accommodated with more extensive family service provisions. This would explain why fertility rates are higher in Western and Northern Europe (Bongaarts 2002; Caldwell et al. 2002; Chesnais 1996; Lesthaeghe 1995) where family services are more extensively funded and available than in Southern and Eastern Europe where family services are scarce. That fertility rates are higher in Western and Northern Europe is also a paradox because Southern Europe, in particular, places significant value on family ties for the provision of resources and support thus, larger families would intuitively be expected. One possible explanation for low fertility in this region is that women's educational and occupational opportunities have expanded such that they now face competing demands between employment and family time (McDonald 2002; Jones and Brayfield 1997; Baxter and Kane 1995). Previous studies suggest that where there are few social support systems addressing family needs and women are assumed to be primary caregivers at the expense of occupational opportunities, women will limit and/or delay childbearing (McDonald 2000; Guerrina 2002). While this argument is compelling, few studies have tested this proposition empirically. 
Here we test the association between child care enrollment, family leave, women's employment, and fertility to see if welfare regimes help explain regional patterns of low fertility. Esping-Andersen (1999, p.35) defines a welfare regime as "the combined, interdependent way in which welfare is produced and allocated between state, market, and family." These differences in family welfare regime contexts are plausibly associated with different fertility outcomes. Specifically, we hypothesize that welfare regimes with more extensive market and government family services are those that will have higher fertility levels. Our results show that in countries where a larger percentage of children are enrolled in day care services, women tend to have more children. We also examine the relationship between women's employment and fertility and show that the association between women's employment and fertility is in fact negative, both at the individual and country level, a result that differs from that found by other researchers using only country-level variables (Brewster and Rindfuss 2000; Rindfuss et al. 2003; Sleebos 2003; Esping-Andersen 1999). Therefore, the correlation between women's total labor force participation and fertility remains negative when controlling for individual-level effects even though child care services may reduce some of the impact of high levels of labor force participation.

We employ a hierarchical Bayesian model to analyze individual- and macro-level determinants of women's realized fertility across twenty developed countries. A multi-level model is employed because social and economic conditions in a country are the context in which individual decisions are made, particularly fertility decisions (McDonald 2000). A hierarchical model allows for the estimation of contextual effects produced by country-level variables, while controlling for variations in individual-level characteristics. The present study is focused on developed nations: even though they have substantial fertility differences, developed countries 
share similar national characteristics such as low levels of mortality (Bagavos and Martin 2000), relatively high levels of female education and employment, and access to contraceptives (Mason 2001). Developed countries also have comparable child care enrollment data, information that is not available for, or in some instances applicable to, developing countries. By concentrating on countries with similar background characteristics, we can more readily isolate the effects of welfare regime differences and minimize the influence of confounding factors.

Our research attempts to methodologically assess the paradox posited by other researchers of fertility: namely, why fertility is so much lower in the familialistic countries of Southern and Eastern Europe. To establish the context for this research, we initially discuss two relevant issues: 1 . National trends in fertility, family size, and establishment; and 2. Trends in women's employment and work-family policies. While our findings suggest that individuallevel characteristics are of primary importance for explaining fertility rates, it is important that these be interpreted within the national context.

\section{$\underline{\text { Trends in Fertility and Family Structure }}$}

\section{The Demographic Transition}

The decline from high levels of mortality and fertility to low levels of mortality and fertility is commonly known as the "demographic transition" (Jones et al. 1997). As early as the 1920s, half of the countries in Europe were at below replacement fertility levels (Frejka and Ross 2001). Fertility levels increased temporarily in the 1950s during a short baby boom in Western and Northern European countries and the English-speaking countries, only to begin the decline again in the 1960s. From the 1950s to the 1990s the total fertility rate in the developed world dropped 44\%, from 2.8 births per woman to 1.57 births per woman (Bongaarts 2002). 
Among developed countries, the highest fertility rates are found in North America (2.00), Oceania (1.8), and Northern Europe (1.67), while the lowest fertility rates are found in Japan (1.41), Southern Europe (1.32), and Eastern Europe (1.28) (Bongaarts 2002). Low fertility is of great significance to individuals and nations due to the restructuring that must take place to accommodate these new trends. A significant population decline could alter the structure of the labor force and cause diminished productive capacity due to the lack of workers. However, lower levels of fertility and increased longevity can increase the demand for women in the labor force due to a smaller labor force, and the shortened span of time women spend bearing and rearing children frees up their time for employment (Mason 1997). Population declines can also place temporary stress on small working populations due to population aging leading to greater needs for health plans and pensions (Mason 2001). Many European countries are already expecting pension costs to double within the next thirty years (Esping-Andersen 1999) and this may not be sustainable.

Very low fertility could partially be the result of a delayed mean age at first birth. Women in the developed world have had a general increase in age at first birth by 2-3 years where fertility is delayed and later "recuperated" (McDonald 2002). When fertility is recuperated, women tend to condense their childbearing into fewer years at later ages. If current low fertility is due to delays in age at first birth, then the fertility rate will rise as women age. However, many women who delay childbirth find that later conditions do not support childbearing (i.e., they are not able to find a suitable partner, or experience unstable employment, financial problems, and/or health complications) or they decide they no longer wish to have children, thus keeping the fertility rate low (McDonald 2002). 
Recuperation rates vary by country and in some the recuperation rate is higher than others (Sleebos 2003). Norway and the Netherlands have higher levels of recuperation while Spain and Italy have very low levels of recuperation, indicating that their very low fertility rate is unlikely to be a result of delayed fertility (McDonald 2002; Lesthaeghe 1995). For the birth cohort of 1950, 67\% of countries have completed cohort fertility of below 2.1 (Frejka and Ross 2001). Of these countries, two thirds have completed cohort fertility below 1.9. Some countries have completed cohort fertility rates as low as 1.66 (Germany), 1.65 (Russia), 1.60 (Spain), and 1.59 (Italy) (Frejka and Ross 2001; Bagavos and Martin 2000). This leaves no possibility for recuperation in fertility, because the women have already passed reproductive ages. These completed cohort fertility differences can be attained through different mechanisms. In some countries it is more unusual to make a transition to a higher order birth while in others there are relatively high levels of childlessness. In some countries it is a combination of both. In Eastern and Southern Europe, total fertility rates have declined, in part, because of a lack of transition to higher order births (Kohler et. al 2002). In Germany and Austria childlessness levels for more recent completed fertility cohorts are comparatively high at $17 \%$ to $18 \%$ (with some projections placing estimates for future cohorts as high as 30\% or more) while in Bulgaria and the Czech Republic childlessness remains closer to 10\% (Rowland 2007; Kohler et. al 2002).

\section{Fertility and the Life Course}

Childbearing is often an expected part of the life course. Most men and women express the desire to have children (Arnold et al. 1975; Zelizer 1985), and pronatalist norms create the expectation that most people should have children (Jones and Brayfield 1997). Such norms tend to have a particularly strong impact on women as the responsibility of childrearing has fallen disproportionately on them. There has been a shift in the peak first birth ages from 20-24 to ages 
25-29 in much of Europe and in the United States and Australia (Frejka and Ross 2001). The mean age at birth in Europe is now 27.1, compared to 24.1 in 1970 (Sleebos 2003). One reason why the mean age at first marriage and childbirth has been rising in countries such as Japan and Italy is that women, once they get married, are expected to "return" to the traditional division of labor, where men are primarily wage earners and women perform most of the household and child care labor (Presser 2001; Tsuya and Mason 1995). This limits their opportunities outside of the home. In addition, in Southern Europe and Japan, fertility outside of marriage is very low, so if marriage is postponed, fertility is likely to be limited and delayed as well (Bagavos and Martin 2000). The expansion of higher education also delays marriage as students are very unlikely to marry or have children (Carlos and Maratou-Alipranti 2000).

Even though fertility and employment preferences interact and change throughout a person's life course (Budig 2003), a downward shift in family size has been widespread in much of the developed world. In the 1960s, first and second order births as a percentage of total births was $64 \%$, and by 1990 this had changed to $84 \%$, with much of the increase being in first order births (Frejka and Ross 2001). Many couples opt to have only one child, as this can grant the benefits and status of being a parent with fewer costs (Bagavos and Martin 2000). The additional benefits of a second child may then be too low to justify the material and non-material costs (Presser 2001). Brewster and Rindfuss (2000) also propose that families become more aware of work-family conflicts after having their first child and this could reduce higher order births.

\section{Fertility and the Work-Family Balance}

McDonald (2000) states that while gender equity is not a sufficient condition for higher fertility, it is a necessary condition in the developed world. As opportunities have opened up for 
women in employment and education, the conflict between career and home responsibilities has deepened, particularly in countries which maintain traditional family arrangements. According to McDonald, "if women are provided with opportunities nearly equivalent to men in education and market employment, but the opportunities are severely curtailed by having children, then on average women will restrict the number of children that they have," resulting in low fertility (2000, p.1). This relationship should hold true unless social support mechanisms mediate the impact of having children. Bagavos and Martin (2000) find that when the gender gap in employment rates is small (due to high availability of child care services), fertility tends to be higher than in countries with wide gender gaps in labor force participation.

Fertility and Women's Employment

By 1970, about half of women ages 20-64, were in the labor force in developed countries (Lesthaeghe 1995). Today, 74\% of childless women work, while $70 \%$ of mothers with one child work, and $62 \%$ of mothers with two children work, though these rates vary significantly by country (Sleebos 2003). Nowhere in Europe does the "breadwinner" model, in which men work full-time and women remain out of the labor force, represent more than $30 \%$ of all households (Esping-Andersen 1999). Women have improved their levels of education, job stability, income, and work experience, giving them a higher status in the workplace (Lesthaeghe 1995; Ermisch 2003). Between 1960 and 1980, men's and women's educational attainment converged, and fertility declined rapidly in many Western and Northern European countries (Caldwell 2001). Many studies have found that a high level of education is negatively correlated with fertility (Mason 2001; Wang and Famoye 1997; OECD 2002). This type of investment in human capital raises both wage potential and opportunity costs (Budig 2003; Caldwell 2001; Mason 2001). As women's wages increase, the opportunity cost of home production increases for women, yet 
women continue to perform most of the housework and child care (Ermisch 2003; McNicoll 2001; Brewster and Rindfuss 2000; Jones and Brayfield 1997; Baxter and Kane 1995).

Children clearly require time investments, and the responsibilities of parenting fall disproportionately on women. Mothers who work full-time spend twice as much time on child care and household labor as do fathers, and housewives spend three times as much time on child care and two and a half times as much time on household labor than do fathers (OECD 2001). As women's household and child care labor increases, wage potential (present and future earnings) decreases correspondingly (OECD 2002). There is evidence that women respond to these circumstances by limiting the number of children that they have (Esping-Andersen 1999). Countries in which female labor force participation has increased the most in recent decades have the lowest fertility rates. The implication is that very low fertility is characteristic of societies where traditional roles for mothers and wives interfere with women's realization of gains from the improvement in education and employment opportunities (McDonald 2002).

Throughout Europe, approximately half of women with children under the age of six work part-time (OECD 2001). Part-time jobs have a large concentration of mothers who, through need or choice, wish to remain employed while being primary care-takers (OECD 2002). Parttime work provides women with a source of income (and some benefits in certain countries) and a flexible schedule. However, part-time work leads to fewer opportunities for advancement (OECD 2002) and concentration in non-managerial, less lucrative occupations (Mandel and Semyonov 2006) and at the macro-level, part-time work creates high levels of job segregation, as in Sweden, the Netherlands, and Norway (Baxter and Kane 1995; Pinnelli 1995). In a study of European family policy, Weiss (2000, p. 138) states:

Part-time work offers women the opportunity to combine both family and employment. However, the traditional division of labor between men and women 
is not really questioned. Women remain primarily responsible for raising children and tending to the household. As a result, their chances for a professional career drop considerably.

It is established in the literature that full time work is associated with lower fertility (Budig 2003; Hakim 2003). The more children women have, the less likely they are to participate in the labor force. Those who participate in the labor force tend to have fewer children (Lesthaeghe 1995; Sundtröm 2000). However, the effects of part-time work do not have as clear-cut results. The effect of part-time work, on the one hand, seems to increase fertility because it allows women to combine parenthood with employment (OECD 2002). On the other hand, part-time work lowers women's wages and occupational attainment, leading to low fertility since the opportunity costs of children remain high. The effect of part-time work could also vary by country, given that the meaning of part-time work and the number of hours considered to be part-time vary by country (Gornick and Meyers 2003). In Scandinavian countries, part-time work is more often available and remunerated on an equal basis with full-time work (Ellingsaeter 2000). In contrast, in Southern and Eastern European countries, part-time work is rarely available and is marginalized. In the United States few part-time jobs provide benefits equaling those of full-time employment (Kalleberg 2000). Yet, in spite of these differences, part-time workers tend to be segregated and paid less than full-time workers and part-time work is often adopted by women as a "combination strategy" to balance work and family (Hakim 2003). As such, we hypothesize:

\section{Hypothesis 1: The effect of part-time work on fertility will be more similar to the effect of being out of the labor force than the effect of full-time work.}

Rindfuss and his colleagues (2003) show that there is a positive correlation of .50 between female labor force participation rates and national fertility rates. While this may appear counter-intuitive, countries with low female labor force participation are thought to have such 
low rates because of the difficulties reconciling work and family responsibilities. In countries where most women enter the labor force, accommodations must take place. Where there is a smaller gap in employment between men and women, the effect of children on women's wages and employment is less severe (Harkness and Waldfogel 1999). When a greater number of women are employed, family policy or market-based services may be more salient in response to women's occupational and familial demands. This, in turn, would increase fertility and labor force participation. Thus, in keeping with past studies we posit the following:

\section{Hypothesis 2(a): Female labor force participation rates will be positively correlated with fertility.}

Although hypothesis 2(a) expresses the relationship most often discussed in the literature, we note that the theory articulated by Rindfuss and others (Brewster and Rindfuss 2000; Rindfuss et al. 2003; Sleebos 2003) is actually more consistent with a moderating effect of female labor force participation on fertility than a direct effect. In particular, if we imagine that the barriers to fertility posed by employment at the individual level are decreased by total female labor force participation, then we would expect labor force participation to have a positive moderating effect on the (negative) effect of individual employment. Because (unlike the articles cited above) our data permits a multi-level analysis, we can examine this hypothesis directly. Specifically:

\section{Hypothesis 2(b): Total female labor force participation will positively moderate the direct effect of individual employment on fertility.}

\section{Fertility and Social Policy}

In 1996, 23 out of 64 countries with below-replacement fertility had policies to raise fertility (Tsui 2001; Caldwell et al. 2002). Countries vary in the level of concern expressed by leadership or popular sentiment on the country's total fertility rate. In some countries the costs to 
implementing social welfare programs are high, fertility is not very low or low rates are perceived as temporary, the population has not yet declined because of population momentum, or immigration has offset the declines in births (Caldwell et al. 2002). In some countries, population decline may be perceived as a positive factor to improve the environment and ease urban crowding (Sleebos 2003; Caldwell et al. 2002). In other countries, intervention is seen as intrusive, and there is opposition to defining a preferable family size and type, because it stigmatizes and discriminates against alternate lifestyle choices (Caldwell et al. 2002). Support for social policy on the basis of gender equity or social welfare is perceived as more acceptable.

Social policies that ease the pressures on working parents may be crucial in enabling individuals to reach their fertility goals without interrupting their occupational goals (Bagavos and Martin 2000). Such policies include access to child care services, maternity leave, paternity leave, parental leave, flexible employment schedules, and paid health benefits. Generally, countries that provide women with fewer opportunities to combine a career with parenthood have very low fertility rates (Caldwell et al. 2002; Esping-Andersen 1999; Chesnais 1998). For example, East Germany's total fertility rate declined by $50 \%$ after reunification with West Germany, at least in part because of the loss of child friendly policies and child care centers (Chesnais 1996; Brewster and Rindfuss 2000). Sweden's total fertility rate had been 2.1 in 1990 when spending on social welfare was high and then decreased to 1.6 in 1996 after significant budget cuts in 1992 (Chesnais 1998; Caldwell et al. 2002).

In one of the most well-known characterizations of European policy regimes, EspingAndersen (1999) identified three types: Liberal, Conservative, and Social Democratic. Although initially developed to address class inequalities rather than family and gender relations (Orloff 1996), his perspective on policy regimes does have a lot to offer to the study of family policy. 
Furthermore, the initial regime types remained robust in subsequent revisions to his work that were more explicit about taking family and gender into account. According to EspingAndersen's typology, Liberal states (i.e., United States and England) are those that focus on individual self-reliance and promote market-based services. Family policies, when available, focus on gender equity in employment but make few provisions for caretaking and benefits (i.e., maternity and parental leave, flexible employment, health care). Social Democratic countries have more comprehensive risk coverage based on citizenship. Provisions tend to be universal entitlements and minimize market dependency. Family policy is well-established through the provision of child care, flexible and part-time employment schedules, paid maternity and parental leave, and health benefits. Examples of these countries include Denmark and Sweden. Conservative states tend to adopt the breadwinner model in which the male head of household is protected though job stability and higher income levels. Few social policies address family needs because it is presumed that women will care for children and the elderly and remain out of the labor force (at least periodically). Benefits that are available tend to be tied to the individual's occupational record. A wider variety of countries are grouped in this typology, including much of continental Europe and Asia.

Within the Conservative typology, Southern European countries (Italy, Spain, Portugal, and Greece) tend to be more familialistic, unemployment rates are higher, market services are costly and difficult to find, and children tend to reside with their parents for much longer periods of time, often until the children are in their late twenties or early thirties (Esping-Andersen 1999; Flaquer 2000; Laaksonen 2000). In Southern Europe, Germany, and Japan, the male breadwinner model still shapes policies (Sleebos 2003). Women are often viewed as dependents and caretakers rather than as independent employees. This limits state intervention in the provision of 
child care and flexible employment while upholding traditional distributions of labor in the home. When conservative family policy is applied, "welfare responsibilities are internalized within the family and this is incompatible with women's demand for economic independence and careers" (Esping-Andersen 1999, p.174). When looking at Esping-Andersen's typologies, it becomes apparent that the countries which provide few family services have the lowest fertility. Southern Europe and the Conservative countries have the fewest provisions for families, and these are the countries with the lowest fertility. Social Democratic countries provide extensive family benefits and have higher fertility. The Liberal countries do not provide many public family benefits, presumably because these can be found in the market. Market services in these countries do not tend to be of high quality, but they are available at a lower cost than in much of Europe (Esping-Andersen 1999) and thus may help offset very low fertility.

Economic incentives such as tax allowances and cash benefits have not proven to be effective in increasing fertility, most likely because of the limited benefit provided to balance the high costs of having children (McDonald 2002; Bagavos and Martin 2000). In a study of 22 developed countries, Gauthier and Hatzius (1997) found that over a twenty-year time span, cash and tax benefits, preferential and subsidized housing, and child benefits only increased fertility by $4 \%$. The effects of maternity and parental leave benefits are mixed but overall appear to be weak predictors of fertility (OECD 2001). Most European countries provide paid maternity leave for 16 weeks, and many provide an extended period of parental leave. However, family leave is not long enough for either parent to provide continuous care up until the child is enrolled in school. In addition, family leave requires that at least one parent temporarily leave work. Since the person most likely to do so is currently the mother, this reproduces gender inequality in labor force participation. (Fathers tend not to make use of parental or paternity leave unless it is for 
short periods of time and paid (Gornick and Meyers 2003; OECD 2001).) Lewis (2006) argues that child care services are more likely to promote female labor force participation and be more gender neutral in its effects than family leave policies. While maternity and parental leave can help parents reconcile work with family obligations and reduce some of the gap in pay between women with children and childless women, long periods of leave can reduce women's labor force participation and career attainment (Waldfogel 1998; Sleebos 2003), increase wage penalties, and result in more unequal distributions of household labor (Morgan and Zippel 2003). Yet because the level of benefit (income replacement and duration of leave) associated with family leave is relatively minimal, we hypothesize:

\section{Hypothesis 3: Family leave will not be associated with fertility.}

Being able to purchase child care weakens the link between women's labor force participation and fertility, particularly when these benefits are subsidized by employers or the government (Ermisch 2003). The availability of child care allows mothers to work and can also encourage women who are out of the labor force to seek further education or employment (Sleebos 2003; Eydal 2000). Child care services appear to be the most effective strategy for ensuring greater equality in accessing the labor force (Greve 2000). The access to child care for children above the age of three is fairly high throughout Europe (average 75\%), but the availability of child care for younger children is very limited in some countries, particularly in Southern Europe (see Table 1) (Sleebos 2003; OECD 2001). Sleebos (2003) reports that the enrollment in child care services for children under the age of three explains $43 \%$ of the variance in total fertility rates for European countries. Child care would seem to be a powerful means of decreasing conflict between work and family responsibilities. Child care for young children is 
particularly important because it does not require a long waiting period for women's return to paid employment. Consistent with this, we hypothesize the following:

\section{Hypothesis 4: Child care enrollment will have a positive effect on individual fertility levels.}

Even given a positive overall relationship, however, child care may not have the same effect in every country because of differences in quality, price, hours of operation, and social norms about the acceptability of child care (Mason and Khulthau 1992; McDonald 2001; EspingAndersen 1999). In a study of the Detroit area, for instance, Mason and Kuhlthau (1992), conclude that child care does not have a significant effect on fertility. Child care constraints only limited the number of children for $8 \%$ of the respondents. However, this study did not include women who did not have children. Women who did not have children could have been those who faced the most severe constraints on child care availability. Excluding these women could thus result in an underestimation of the effect of child care on fertility.

Child care may also not have an effect on fertility when parents are unwilling to place their children in day care. For Australia, McDonald (2001) found that long hours of care (over 20 per week) were considered inappropriate for children under the age of four by $71 \%$ of men and $65 \%$ of women. If much of the population is opposed to using child care facilities when children are very young, then the provision of child care for this age group would not be expected to increase fertility.

\section{$\underline{\text { Data }}$}

To assess the impact of family leave, child care enrollment, and women's employment on fertility across national contexts, we employ both individual-level data and country-level data. For individual-level data we use the 1995-1997 wave of the World Values Survey (WVS) and 
the 1999-2000 wave of the European Values Study (EVS). These two surveys are national, multi-stage, random probability samples and use very similar, standardized questionnaires to gather data. Separate model fits were performed for each data set, and the results were not qualitatively altered by merging the two data sets; results shown here are from the merged sample. A total of twenty countries are included the analysis. Specifically, we use seventeen countries from the EVS and three countries from the WVS (countries that were not available from the EVS). The EVS countries are Austria, Belgium, Czech Republic, Denmark, Finland, France, Germany, Great Britain, Greece, Ireland, Italy, Netherlands, Portugal, Slovakia, Slovenia, Spain, and Sweden. The countries provided by the WVS are Australia, Norway, and the United States. Other countries are excluded due to missing values or lack of macro-level data. We restrict our sample to women of childbearing ages (18 to 45) for a total sample size of 7,080 cases.

Data on child care enrollment for children under the age of four is provided by the OECD. The data on child care includes any type of child care that is reported to the government by individual families. This includes private or public day care, play-groups, family centers, early childhood education through the educational system, or registered baby-sitters and childminders. This does not include provision of care by a member of a child's immediate family, as this is generally considered an informal arrangement and is often not recorded by the government. National statistics offices collected original data on child care arrangements between the years of 1997 and 2000. In the United States (1995) and Australia (1999), household surveys were used to gather information on child care arrangements.

Sufficient data is not available to differentiate between public and private provision of care or quality of care but for the analyses undertaken, this differentiation is not crucial because 
we are interested in child care as a form of substitute care. Substitute care is often made available through government-sponsored programs, even if the role of the government varies by country. The United States, for instance, provides government funds for child care services to low-income families (i.e., Head Start) and through tax rebates whereas Sweden has more universal and comprehensive government funding for day care services. Both public and private care provide some measure of reconciliation between work and home responsibilities and it is more important to incorporate the scarcely available child care data rather than limit explorations by type and quality of care, information that is not available for most of our sample. It is also not entirely straightforward how child care services are to be classified. Much depends on whether one wants to classify the child care provider as government operated or privately operated or whether it is privately or government funded (e.g., direct funding or through rebates or subsidies provided to families). These undertakings are best left for a more in depth analysis of child care with less of a comparative perspective.

Because data for child care services have only been gathered recently, the effect of child care on older women may be overestimated in the sample. To provide some insight into the magnitude of change in child care enrollment, data from 1993-1994 were compared to current data for those countries in which they were available. Out of 14 countries for which data were available, four experienced significant change (see Table 2). Results for older women, especially the four countries that experienced significant change (Sweden, Great Britain, Denmark, and Finland), should be interpreted with caution because their childbearing predates the child care environment examined. On the other hand, ten countries did not experience any significant change (less than $10 \%$ change) indicating that estimates may be more accurate in these countries. 
The data on women's labor force participation rate for the ages of 25-54 is drawn from Eurostat European Union Labour Force Survey (European Commission 2002), the Current Population Survey (United States), and the Labour Force Survey (Australia). The total labor force participation rate is calculated by dividing the number of women employed by the total number of women in the corresponding age bracket.

\section{Dependent variable}

The dependent variable for this study is the total number of children ever born (realized fertility), at the time of the interview. This data is available for 7,080 women ages $18-45$, and is provided by the EVS and the WVS.

\section{Individual-level variables}

Individual-level variables are those obtained from the EVS and WVS. These include: Current marital status, highest level of education, employment status, parental co-residence, and an attitudinal variable - whether the respondent believes that "women need children in order to be fulfilled". ${ }^{1}$ In this analysis, current marital status is converted into three dummy variables: married, cohabiting, or divorced. The omitted category consists of people who have never married. Due to differences in educational systems across different countries, we coded respondents dichotomously as having a high level of education (1) if any post-secondary schooling is completed (i.e., university-level degree/certificate and higher) and (0) otherwise. We converted employment status into four dummy variables representing full-time work, part-time work, student, and unemployed. The omitted category is women who are housewives and/or otherwise out of the labor force. Parental co-residence has previously been found to be

\footnotetext{
${ }^{1}$ Two individual-level variables, religion and household income (women's income was not available), were excluded in the final model as they were not significant. Household income was provided in 10 categories ranging from very low income to very high income levels. These were standardized to account for cross-national differences in income levels.
} 
negatively correlated with fertility (Flaquer 2000). To control for this, we code the respondent as 1 if she lives with her parents and 0 if not. Self-reported attitudes on the "need for having children" are included to determine if fertility corresponds to these perceived needs. People who see children as more central to a person's life are likely to have higher fertility than those who do not. In particular, when asked, "Do you think that a woman has to have children in order to be fulfilled or is this not necessary?" respondents answering in the affirmative were coded 1, with those answering negatively coded 0 (no option of indifference was provided).

\section{Macro-level variables}

The macro-level variables employed here are the percentage of children ages three and younger who participate in some form of child care; family leave; and women's total labor force participation ${ }^{2}$. Child care is measured as the percentage of children under the age of four in a given country who attend or are enrolled in any type of child care arrangement, whether from a private or public source, excluding care by immediate family members. Family leave is measured as the total number of weeks parents are entitled to take off from work at the birth or adoption of a child and/or to care for young children. Further analysis was done by including benefit/payment levels; since these were not found to be significant, paid and unpaid leave are combined. Women's total labor force participation rate is the percentage of women between the ages of 25 and 54 who are employed (either part-time or full-time).

\footnotetext{
${ }^{2}$ Additional macro-level variables were examined, but were not found to be significant, thus were excluded from the final model. These include child care enrollment for children between the ages of 4 and 6 , various combinations of maternity and parental leave (amount of leave available and portion remunerated), the total unemployment rate, and the Gender Empowerment Measure. The Gender Empowerment Measure (GEM) is an index developed by the United Nations. The GEM gives a rating between 0 and 1 to each country based on the number of women who hold parliamentary and legislative seats, technical jobs, managerial jobs, and professional jobs, as well as the ratio of female to male estimated earned income. This index was not found to be significant and each individual component was also not significant. In addition, women's labor force participation rate was separated into full-time and parttime participation and results were not significantly different than those obtained with the total labor force participation rate used presently. All results are available upon request.
} 


\section{Methods}

We employ a hierarchical Bayesian model to adequately test individual-level and country-level variables. A hierarchical model allows data to be nested in several levels, and by recognizing that individuals are nested into countries a hierarchical model allows for the modeling of heterogeneity (Hoffman 1997). A conventional ordinary least-squares regression in which individual-level data are pooled across all countries could result in biased coefficients (Raudenbush and Bryk 2002) and would not show the differences in effect and magnitude that individual-level variables can have in different countries. (As we will show, being married or a full-time worker, for instance, does not have the same magnitude of effect in each country.) A Bayesian model is also more advantageous when the number of higher-level units is small (Raudenbush and Bryk 2002) as is the case in our study. Furthermore, as the dependent variable for this study (realized fertility at the time of the interview) is both discrete and bounded, a conventional (e.g., OLS) linear model is clearly inappropriate. While a hierarchical variant of a standard hazard analysis might seem reasonable, we are also limited by the lack of detailed fertility histories: we cannot be certain when respondents' births took place, except inasmuch as they were prior to the time of the interview. We also know that fertility hazards change dramatically across the life course, ruling out a model based on constant hazards. As a compromise between the limitations of available data and the requirements of prior knowledge, we here model fertility as an inhomogeneous Poisson process with piecewise constant hazards ${ }^{3}$. Specifically, we model age effects on fertility via a series of age-specific hazard multipliers. Age hazard multipliers are estimated for six age categories of equal length: 15-19, 20-24, 25-29, 30-

\footnotetext{
${ }^{3}$ Inhomogeneous Poisson models are widely used in survival analysis (see, e.g., Cox and Oates, 1984; Blossfeld and Rohwer, 1995): our restriction lies in the use of a piecewise constant rate function whose time-varying parameters are homogeneous with respect to the respondent population. Detailed fertility histories would allow for a more finegrained resolution of the hazard curve.
} 
34, 35-39, and 40-45. For the purposes of the model, the age hazard multipliers are assumed to be constant in each age category and are shared across countries (as with a synthetic cohort model). For example, all other things being equal, a woman who is twenty is expected to have the same hazard as a woman who is twenty-three. While it would be desirable to have a more fine-grained parameterization, the data does not supply enough information to do so reliably; nevertheless, the results shown here appear reasonably robust to choice of categories. The agespecific hazard multipliers are interpreted relative to the reference category (ages 25-29) for reasons of model identifiability. Multiplier estimates are thus evaluated based on the extent to which they are higher or lower than the hazard for the third age category.

To account for overall national fertility differences, baseline fertility hazards (determined by country-specific offsets), are assigned to each individual based on country membership. Each country's offset is taken to be a priori normally distributed with a mean given by a linear combination of country-level covariates and coefficients. All individuals in a particular country are assigned the same offset and hence can be thought of as "starting out" with the corresponding baseline fertility hazard. This baseline fertility hazard is then modified (increased or decreased depending on the direction of the effect) by age effects and individual-level covariates. Individual fertility is predicted by multiplying and then exponentiating the individual-level covariates and coefficients, country-specific offsets, and age-specific hazards according to the amount of time the individual spent in each age interval (exposure time).

\section{Formal Modeling Framework}

Formally, our model is constructed as follows. We begin by defining a series of adjacent, disjoint age intervals, $I_{1}, \ldots, I_{n_{\alpha}}$, such that all intervals are of equal length. For each such 
interval, we posit a nonnegative parameter $\alpha_{i}$ such that for some $r$ in $1, \ldots, n_{\alpha}$, and for $\alpha_{r}=1$, $i \neq r$, we have the following prior structure:

$$
p\left(\alpha_{i}\right) \propto 1
$$

and

$$
p(\alpha)=\prod_{i=1}^{n_{\alpha}} p\left(\alpha_{i}\right)
$$

These $\alpha$ parameters are interpreted as age-specific hazard multipliers for intervals $I_{1}, \ldots, I_{n_{\alpha}}$ with the $r$ th interval serving as a reference category. While these parameters are shared across countries, we also posit a country-specific offset, denoted $\beta_{0 i}$ for $i$ in $1, \ldots, m$, where $m$ is the number of countries in the data set. These offsets are taken to arise from an a priori normal distribution whose mean is given by a linear combination of country-level covariates, i.e.

$$
p\left(\beta_{0 i}\right)=N\left(\beta_{0 i} \mid Z_{i \bullet} \gamma, \sigma_{\gamma}^{2}\right),
$$

where $Z$ is an $m$ by $n_{c}$ covariate matrix ( $n_{c}$ being the number of country-level covariates), $\gamma$ is a parameter vector of length $n_{c}$, and $\sigma_{\gamma}^{2}$ is a non-negative real parameter. While $Z$ is assumed known, we take $\gamma, \sigma_{\gamma}^{2}$ to be uncertain with noninformative prior density.

$$
p\left(\gamma, \sigma_{\gamma}^{2}\right) \propto \sigma_{\gamma}^{-2}
$$

Taken together with $\alpha$, the offset parameters provide a time-varying, country-specific baseline hazard (as is shown below); fixing one element of $\alpha$ to a constant (see above) is sufficient to permit model identification in this case. 
In addition to these baseline effects, we also posit an individual-level covariate set $X$ having $n_{b}$ elements, with which we associate pairs of hyperparameters $\mu_{i}, \sigma_{i}^{2}$. The a priori distributions of these hyperparameter pairs are given by

$$
p\left(\mu_{i}, \sigma_{i}^{2}\right) \propto 1
$$

for $i$ in $1, \ldots, n_{b}$. Associated with each covariate is a collection of $\beta$ parameters, reflecting country-specific covariate effects. The conditional relationship of the $\beta$ s to the hyperparameters is specified by

$$
p\left(\beta_{i j} \mid \mu_{i,} \sigma_{i}^{2}\right)=N\left(\beta_{i j} \mid \mu_{i,} \sigma_{i}^{2}\right)
$$

for $i$ in $1, \ldots, n_{b}, j$ in $1, \ldots, m$. Thus, $\mu_{i, \text { and }} \sigma_{i}^{2}$ can be interpreted as the mean and variance (respectively) for a hypothetical population from which the country-specific effects for the $i$ th covariate are drawn.

Given these parameters, the likelihood of the realized fertility vector (i.e., the vector containing the number of births per respondent), $y$, is as follows. For the $i$ th of $n$ respondents, let $\varepsilon_{i}$ be a vector of exposures, corresponding to the time spent by said respondent in each of the $n_{a}$ age intervals. In addition, let $c$ in $\{1, \ldots, m\}^{n}$ be a vector of individual country memberships, such that $c_{i}$ corresponds to the index associated with the country membership of the $i$ th respondent. Then the likelihood of the $i$ th observation is given by

$$
p\left(y_{i} \mid \alpha, \beta, \varepsilon, X\right)=\operatorname{Pois}\left(y_{i} \mid \exp \left(\beta_{0 c_{i}}+X_{i \bullet} \beta_{\bullet}\right)\left(\varepsilon_{i}^{T} \alpha\right)\right)
$$

for $i$ in $1, \ldots, n$. Thus, fertility is assumed to arise from an inhomogeneous Poisson process with a piecewise constant rate function which depends on age, individual covariates, and 
country membership. The assumption that respondents' realized fertilities are conditionally independent combined with the previously defined prior structure then leads to the joint posterior

$$
p\left(\alpha, \beta, \mu, \sigma, \gamma, \sigma_{\gamma} \mid y, \varepsilon, X, Z\right) \propto\left(\prod_{i=1}^{n} p\left(y_{i} \mid \alpha, \beta, \varepsilon, X\right)\right)\left(\prod_{i=1}^{n_{b}} \prod_{j=1}^{m} N\left(\beta_{i j} \mid \mu_{i}, \sigma_{i}^{2}\right)\right)\left(\prod_{i=1}^{m} N\left(\beta_{0 i} \mid Z_{i \bullet} \gamma, \sigma_{\gamma}^{2}\right)\right) \sigma_{\gamma}^{-2}
$$

Although we cannot sample directly from this distribution, we may use Markov Chain Monte Carlo (MCMC) methods to obtain approximate draws. For this analysis, we employed a combination of Gibbs and sequential draw Metropolis sampling to simulate the joint posterior for each model tested (see Gilks et al. (1996) or Gamerman (1997) for a review of this approach). Maximum likelihood estimates were used to provide seed values for the Markov chain.

Due to the size and complexity of the models under consideration, the full slate of analyses conducted cannot be shown here. In particular, a variety of models based on the previously identified covariate set were considered, with the final model being selected based on the cross-validation predictive likelihood (CVPL) (Gefland 1994). The CVPL-favored model (shown below) was also preferred under other selection criteria (e.g., the deviance information criterion (Gelman el al. 2004); effects shown here were qualitatively similar under alternative models).

While, for reasons of familiarity, we mimic the presentation style of frequentist $p$-values, quantiles shown are posterior probabilities rather than quantiles of a hypothetical null distribution. Thus, the statement that $p\left(\mu_{i}>0\right)=0.05$ here means that $\mu_{i}$ is estimated to have a $95 \%$ chance of being less than or equal to 0 (given the data and prior structure) ${ }^{4}$. Similarly, $95 \%$ posterior probability intervals provide a range such that the relevant estimand lies in the range

\footnotetext{
${ }^{4}$ Contrast this with the (loosely) analogous frequentist statement that the probability of seeing an estimate of $\mu_{i}$ at least as small as that observed under the null hypothesis of $\mu_{i}=0$ is equal to 0.05 .
} 
with probability 0.95 (rather than a random interval with $95 \%$ coverage). The ability to make such direct statements of posterior probability - as opposed to statements about hypothetical replications - is an advantage of the Bayesian approach (Robert 1994).

\section{$\underline{\text { Results }}$}

Overall we find that individual-level variables help to explain fertility differences, but are not sufficient to account for cross-national differences in fertility rates. Even after controlling for individual-level characteristics, country-level variables such as child care enrollment and female labor force participation rates have a significant association with fertility (see Table 3). In addition, individual-level characteristics do not have the same magnitude of effect in every country.

\section{Individual-level Effects}

Across countries, the strongest predictors of fertility are marital and employment status. Being married, for instance, increases fertility by an expected factor of 3.3 (see Table 3). This positive effect is found within all countries, although the magnitude of the increase varies significantly (see Table 4). The effect of being married is strongest in the Eastern and Southern European countries - increasing by a factor of 3 or higher - and weakest in the United States and Great Britain, where being married is only associated with slight increases in fertility. The effect of cohabitation on fertility is not significantly different from single status in any country sampled. The expected effect of being widowed, divorced, or separated, on the other hand, was very similar to that of being married. This likely reflects the presence of children from previous relationships, which would produce the observed positive association with fertility. Thus, our 
analysis supports the notion that the salient marital status distinction with respect to fertility is between those who are or have been married, and those who have never married.

Employment status is also a significant predictor of fertility. Full-time work decreases fertility to a greater extent than part-time work (on average) while remaining out of the labor force is positively associated with fertility. This is in line with prior research findings (Lesthaeghe 1995; Sundtröm 2000; Budig 2003) showing that participation in the labor force (full-time or part-time) decreases fertility. Overall, the average decrease in fertility for full-time workers is approximately $30 \%$. Part-time work, by contrast, appears to decrease fertility by $15 \%$. This does not lend support to Hypothesis 1 (i.e., that the effect of part-time work is more similar to the effect of being a housewife than a full-time worker). This does, however, vary by country. In six countries (Germany, Austria, Great Britain, Netherlands, Australia, and Norway), the effect of working part-time work is much more similar to that of a housewife than a full-time worker. In several of these countries, part-time hours are relatively short - in some even marginal as in the Netherlands. In Spain and Greece, by contrast, the effect of part-time work on fertility is more similar to that of full-time work.

Effects for individual-level control variables appear to be consistent with previous research findings (Esping-Andersen 1999; Flaquer 2000; Mason 2001; Wang and Famoye 1997; OECD 2002). Parental co-residence on average decreases fertility by $88 \%$. Agreeing that "it is necessary for women to have children in order to be fulfilled" leads to an average fertility increase of $9 \%$ as opposed to believing that having children is unnecessary. Having a high level of education (university degree or certificate and above) decreases fertility by $18 \%$ when compared to those who have less education. Being a student decreases fertility substantially $99 \%$ on average, though there is a wide range of effects across countries (see Table 4). The effect 
of unemployment (versus the reference category of "housewife") is small or not statistically significant in most countries but leads to an average fertility decline of $10 \%$ across the whole sample.

\section{Country-level Effects}

As expected, country-level effects are consequential. For each percentage of increase in child care enrollment, the country offset is increased by an average of $2 \%$ (see Table 3 ). Thus, while a small increase in child care enrollment would not be expected to increase fertility substantially, increasing the enrollment of children in Southern European countries with very low child care enrollment to a level similar to that of the Scandinavian countries could have a significant impact on fertility rates. For instance, holding all other factors constant, if Italy were to increase its enrollment from $6 \%$ to $64 \%$, to match that in Denmark, the realized fertility per woman would be predicted to increase by an average of 0.97 children. Even if the increase in child care services were moderate and Italy attained the child care enrollment rate of Belgium, which is $30 \%$, fertility for Italian women could increase by 0.27 children per woman. Thus we find significant support for Hypothesis 4 (i.e., that child care has a significantly positive effect on fertility). An important caveat to keep in mind is that this is the expected effect of child care services according to this model, holding all factors constant. Other, unmeasured characteristics present in the nations in which child care services are available and perceived as suitable caretaking alternatives could mitigate the effect of increasing child care in the absence of other types of social and cultural changes.

Controlling for individual factors and child care variables, the expected effect of women's total employment rates on fertility is negative, a finding which differs from those 
obtained by macro-to-macro studies ${ }^{5}$ which show that the association between women's labor force participation and the total fertility rate reversed and became a positive correlation during the 1980s (Brewster and Rindfuss 2000; Rindfuss et al. 2003; Sleebos 2003; Esping-Andersen 1999). Here we find that each percent increase in women's total employment rate multiplies the offset by -.04 , thus decreasing expected fertility by approximately $4 \%$. This contrast in findings may stem from the fact that the above-mentioned studies used the country-level total fertility rate, while this study directly models individual-level fertility. Our results are also consistent with those reported by Kögel (2004) who finds that the correlation between total labor force participation and the total fertility rate remains negative when controlling for additional countrylevel effects, although the magnitude of the association varies by region. To assess whether the negative association between fertility and labor force participation in this study is due to the child care variables, the model was estimated excluding these variables. The association between fertility and macro-level employment rates remained significantly negative (results available upon request). Thus, we do not find support for Hypothesis 2(a), which states that as women's labor force participation rates increase, individual fertility will increase as well. It is interesting to note, in this regard, that the positive effect of child care services does not appear to fully compensate for the effect of labor force participation rates on a 1:1 basis, though the former would soften the effect of the latter.

With respect to Hypothesis 2(b) (the moderating effect of total female labor force participation rates), our results also run contrary to our initial predictions. Examination of the correlation between total female labor force participation rates and the (individual) full-time employment effect across countries indicates that the moderating effect is most likely negative.

\footnotetext{
${ }^{5}$ Conducting a pure macro-to-macro analysis on the data used here yields results similar to those cited.
} 
Although the magnitude of the correlation does not appear to be large (median of - 0.25 , IQR of 0.20 ), the posterior probability that the correlation is less than zero is approximately $92 \%$.

On average, this correlation accounts for approximately $7.9 \%$ of the cross-national variance in full-time employment effects; thus, while the impact of female labor force participation rates is non-negligible, it clearly does not provide a complete explanation of crossnational differences in employment effects. It is also noteworthy that no significant correlation was observed for part-time employment, suggesting that this phenomenon is limited to full-time work. Taken together with the results for Hypothesis 2(a), these findings would seem to undercut the "barrier reduction theory." Although the uniformly negative effect of total female labor force participation rates on individual fertility has many possible explanations, one factor may be the increased opportunities for occupational attainment (in terms of income, status, autonomy, etc.) for women in economies with high participation rates. Thus, "economic enablement" may play a more central explanatory role vis a vis women's fertility (so far, at least) than the gradual reduction of barriers to fertility among working women ${ }^{6}$. Factors such as the association of participation rates with other, unmeasured characteristics of those countries (i.e., division of household labor, availability of market-based services, etc.) could also be implicated.

Disentangling these effects is an important avenue for future research.

The effect of family leave on fertility is not significant, a finding which is in agreement with previous studies (Gauthier and Hatzius 1997; OECD 2001). This confirms Hypothesis 3, (i.e., family leave has no effect on fertility). Maternity leave, although usually paid, is of short duration and would not be of sufficient duration to provide care for young children. Parental leave, which in some countries is available for up to a few years, is not fully compensated and

\footnotetext{
${ }^{6}$ By turns, we would expect that the continued expansion of economic opportunities for women within the developed world may eventually saturate this effect, leading to greater relative importance for issues such as workfamily balance. Whether this transpires in the coming decades remains to be seen.
} 
requires that one parent (almost always the mother) exit the labor force for an extended period of time (if care is to be provided for young children until they begin school). This reduces women's job attachment and labor force participation (Waldfogel 1998; Sleebos 2003) and can result in a loss of wages and occupational attainment. Women will then be reluctant to have children where other sources of caretaking are not available.

\section{$\underline{\text { Discussion and Conclusion }}$}

Our findings underscore the importance of including both country-level and individual characteristics when modeling women's fertility. Importantly, individual attributes do not act identically across national contexts, and considerable differences persist even after controlling for these effects. In particular, aggregate female labor force participation rates and child care enrollment appear to exert a non-negligible effect on national fertility rates. Previous studies have indicated that there is a demand for mechanisms to resolve conflicts between family and work roles. This study suggests that child care services may act in this capacity to some extent, while family leave does not seem to have a comparable effect.

Government officials, preoccupied by declining fertility, have sought out solutions to the issue of population decline and its potential impact on the age structure of the population and resulting effects on the workforce, productivity, and retirement pensions. Some countries have provided tax incentives for having children, others provide direct cash subsidies, while others look to work-family policies. It is crucial that the effect of these measures be understood properly to determine which policies will and will not be effective and what type of effect they each might have. Prior research has not shown tax and cash subsidies to be effective in addressing fertility issues (Gauthier and Hatzius 1997). Here we present among the first cross- 
national studies on the fertility-relevant effects of family leave and child care enrollment. We find that child care services are an effective means for increased fertility and they help soften some of the effects of the expansion of women's labor force participation. We also provide a more nuanced examination of the association between fertility and women's labor force participation. While prior studies have shown that fertility is higher in countries with high rates of female labor force participation (Brewster and Rindfuss 2000; Rindfuss et al. 2003; Sleebos 2003; Esping-Andersen 1999), we show that when controlling for individual-level attributes, the association is strongly negative. In terms of work-family conflict, the positive effects of being in a country with high female labor force participation (i.e., more accommodations at work, more family-friendly services) may not outweigh the costs of having children, such as financial or career attainment costs. However, as countries with "lagging" female employment rates catch up, child care may be a promising solution to avoid very low fertility. This is particularly true for Southern European and Asian countries where female employment is increasing and fertility declining in the midst of weak work-family policies.

It has been suggested that observed work-family tradeoffs are regarded as suboptimal by a non-negligible fraction of women in the developed world (OECD 2001). Women in many societies are faced with taxing demands and may choose to have fewer children than they would otherwise, if more work-family benefits were offered or the division of household labor was more egalitarian. Our findings suggest that child care services can mitigate some of the trade-offs created by these dual demands. In so far as the fertility decline is due to changing norms regarding family size or the desire not to have any children, there may be limits to this mitigating effect. For instance, there is some evidence that the ideal family size has dropped below two in some countries (Goldstein et al. 2003). On the other hand, for those individuals who are having 
fewer children than what they would like due to work-family time constraints, increasing the availability of child care may improve the compatibility between employment and parenthood.

Low fertility remains a significant modern issue that entails a variety of changes and accommodations. Here we highlight one potential avenue for further research: work-family policies. Our analyses are limited by the availability of the data that is currently available. It would be ideal to have more thorough child care data and data for more countries and at several points in time. Unfortunately, data for cross-national studies on child care are extremely scarce. As more data are gathered it would be very enlightening to see whether the association between fertility and women's employment holds over time and if its posited effect increases or decreases in importance over time. Our speculation would be that macro-level factors have grown in importance over time because of the increase in women's labor force participation. More detailed data will allow for further teasing out of the effects of women's employment and child care provision to address the increasingly common demographic trend that is below-replacement fertility. 
Table 1: Child Care Enrollment Rates and Employment Patterns in Europe, Australia, and the United States for the Years 1997-2001

\begin{tabular}{|c|c|c|c|c|c|}
\hline Country & $\begin{array}{l}\text { Total Fertility } \\
\text { Rate }^{a}\end{array}$ & $\begin{array}{l}\text { Child Care } \\
\text { Ages } 0-3 \%{ }^{b}\end{array}$ & $\begin{array}{l}\text { Part-time } \\
\text { Employment } \%^{c}\end{array}$ & $\begin{array}{l}\text { Full-time } \\
\text { Employment } \%^{d}\end{array}$ & $\begin{array}{l}\text { Total Labor Force } \\
\text { Participation } \\
\text { Rate } \%{ }^{e}\end{array}$ \\
\hline Italy & 1.2 & 6 & 23 & 38 & 51 \\
\hline Spain & 1.2 & 5 & 17 & 38 & 51 \\
\hline Czech Republic & 1.2 & 1 & 6 & 56 & 74 \\
\hline Slovenia & 1.2 & 60 & 6 & 57 & $63^{*}$ \\
\hline Germany & 1.3 & 10 & 34 & 47 & 71 \\
\hline Greece & 1.3 & 3 & 9 & 40 & 53 \\
\hline Austria & 1.4 & 4 & 24 & 51 & 74 \\
\hline Slovakia & 1.4 & 46 & 3 & 50 & 65 \\
\hline Portugal & 1.5 & 12 & 15 & 58 & 74 \\
\hline Netherlands & 1.5 & 6 & 57 & 42 & 71 \\
\hline Belgium & 1.5 & 30 & 35 & 43 & 68 \\
\hline Sweden & 1.5 & 48 & 21 & 60 & 82 \\
\hline France & 1.7 & 29 & 24 & 50 & 70 \\
\hline Great Britain & 1.7 & 34 & 41 & 50 & 73 \\
\hline Denmark & 1.7 & 64 & 24 & 63 & 81 \\
\hline Finland & 1.7 & 22 & 14 & 62 & 78 \\
\hline Australia & 1.8 & 15 & 41 & 33 & 67 \\
\hline Norway & 1.8 & 40 & 34 & 57 & 82 \\
\hline Ireland & 1.9 & 38 & 32 & 46 & 53 \\
\hline United States & 2.0 & 54 & 18 & 57 & 74 \\
\hline
\end{tabular}

a Data on the total fertility rate for the years 1995-2000 were provided by the United Nation's Human Development Indicators for demographic trends. These data were gathered from national census and registration reports and evaluated for accuracy and completeness by the Statistical and Population Divisions of the United Nations. $b$ Data were provided by the Organization for Economic Cooperation and Development (years 1997-2000). Original data were gathered by national statistics offices responsible for the collection of data on child care arrangements for each family. In the United States and Australia household surveys are used to gather information on child care arrangements.

c Part-time employment is defined as less than 30 hours per week (35 in Australia). Data are provided by the Organization for Economic Cooperation and Development (2002). Data were gathered from labor force surveys (Eurostat European Union Labour Force Survey and national labor force surveys (Europe), Current Population Survey (United States), Labour Force Survey (Australia)).

$d$ Full-time employment is defined as working 30 hours or more per week. Data are provided by the Organization for Economic Cooperation and Development (2002). Data were gathered from labor force surveys (Eurostat European Union Labour Force Survey and national labor force surveys (Europe), Current Population Survey (United States), Labour Force Survey (Australia)).

$e$ Total labor force participation for women between the ages of 25-54. The figure is calculated by dividing the number of women employed by the total number of women in the corresponding age bracket. Data are provided by the European Commission and were originally gathered by Eurostat and national labor force surveys for the year 2001.

* Data for Slovenia are provided by the United Nations Economic Commission for Europe. Data were gathered with the use of a standardized questionnaire by the Statistical Office of the Republic of Slovenia. 
Table 2: Percentage Change in Child Care Services Enrollment between 1993-2000

\begin{tabular}{|c|c|c|c|c|c|}
\hline \multirow{2}{*}{$\begin{array}{l}\text { Country } \\
\text { Czech Republic }\end{array}$} & \multicolumn{2}{|c|}{$\begin{array}{l}\text { Child Care Ages } \\
0-3 \% 1993-1994{ }^{a}\end{array}$} & \multicolumn{2}{|c|}{$\begin{array}{l}\text { Child Care Ages } \\
0-3 \% 1997-2000^{b}\end{array}$} & Change \\
\hline & & & & 1 & -- \\
\hline Greece & & 3 & & 3 & 0 \\
\hline Austria & & 3 & & 4 & +1 \\
\hline Spain & & 2 & & 5 & +3 \\
\hline Italy & & 6 & & 6 & 0 \\
\hline Netherlands & & 8 & & 6 & -2 \\
\hline \multirow[t]{3}{*}{ Germany } & & & United: & 10 & $+1 /-5$ \\
\hline & West: & 2 & West: & 3 & \\
\hline & East: & 41 & East: & 36 & \\
\hline Portugal & & 12 & & 12 & 0 \\
\hline Australia & & & & 15 & -- \\
\hline Finland & & 32 & & 22 & -10 \\
\hline France & & 23 & & 29 & +6 \\
\hline Belgium & & 30 & & 30 & 0 \\
\hline Great Britain & & 2 & & 34 & +32 \\
\hline Ireland & & & & 38 & -- \\
\hline Norway & & 31 & & 40 & +9 \\
\hline Slovakia & & & & 46 & -- \\
\hline Sweden & & 33 & & 48 & +15 \\
\hline United States & & & & 54 & -- \\
\hline Slovenia & & & & 60 & -- \\
\hline Denmark & & 48 & & 64 & +16 \\
\hline
\end{tabular}


Table 3: Individual and Macro-level Effects on Fertility for Women Ages 18-45

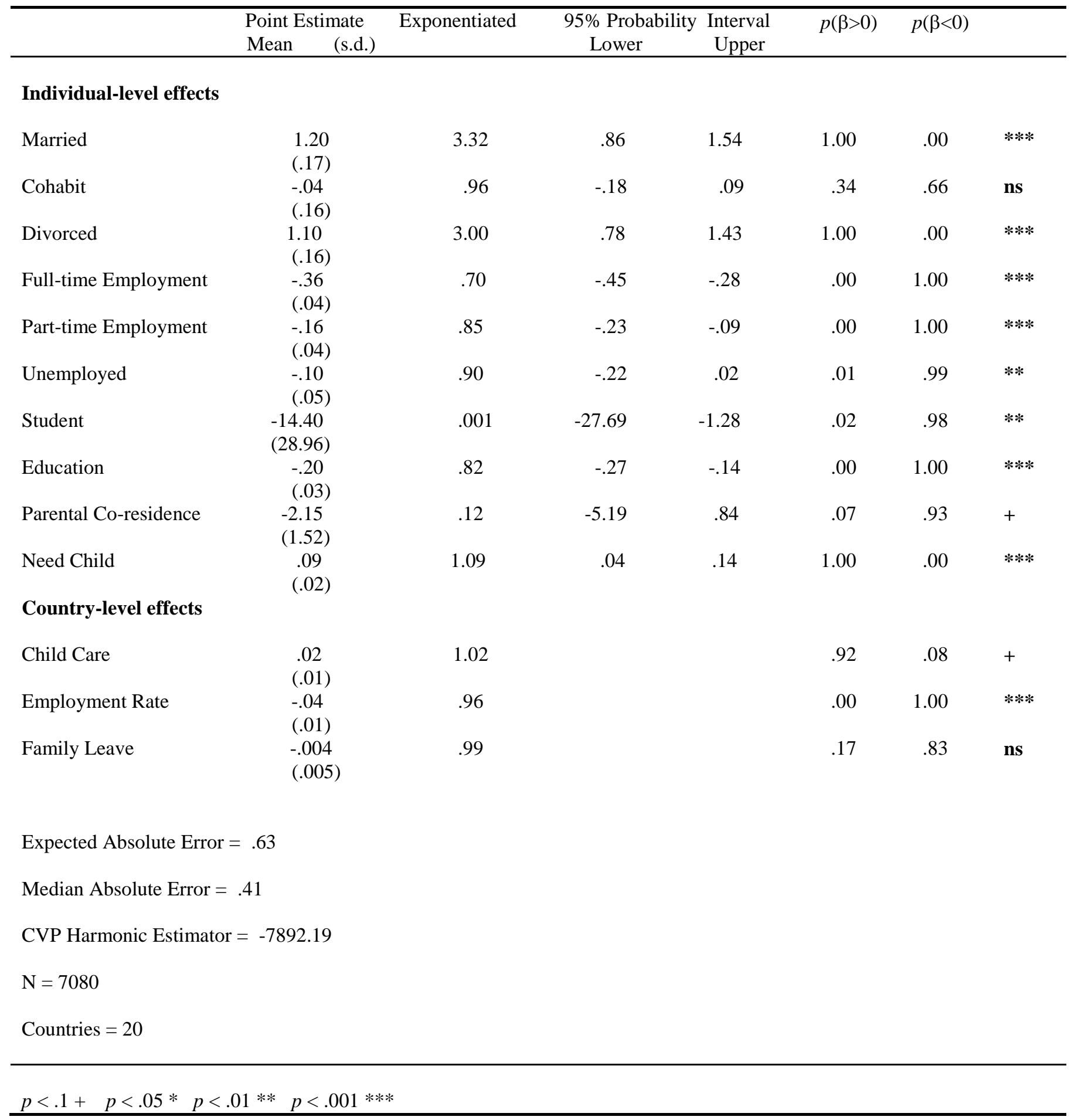


Table 4: Individual-level Point Estimates (Posterior Means) by Country

\begin{tabular}{|c|c|c|c|c|c|c|c|c|c|c|c|c|}
\hline \multirow{2}{*}{ Country } & \multirow[b]{2}{*}{ TFR } & \multirow{2}{*}{$\begin{array}{l}\text { Country } \\
\text { Offset }\end{array}$} & \multicolumn{3}{|c|}{$\begin{array}{c}\text { Marital Status } \\
(\text { Reference category }=\text { Single })\end{array}$} & \multicolumn{4}{|c|}{$\begin{array}{c}\text { Employment Status } \\
\text { (Reference category }=\text { Housewife) }\end{array}$} & \multirow[b]{2}{*}{ Education } & \multirow{2}{*}{$\begin{array}{l}\text { Parental } \\
\text { Co-residence }\end{array}$} & \multirow{2}{*}{$\begin{array}{l}\text { Need } \\
\text { Child }\end{array}$} \\
\hline & & & Married & Cohabit & Divorced & Full-time & Part-time & Unemployed & Student & & & \\
\hline Italy & 1.2 & -3.43 & $1.39^{* * *}$ & -.05 & $1.20 * * *$ & $-.32 * * *$ & $-.17 * * *$ & $-.19 *$ & -.23 & $-.21 * * *$ & $-.80^{* * *}$ & $.09 *$ \\
\hline Spain & 1.2 & -3.73 & $1.90^{* * *}$ & -.03 & $2.14 * * *$ & $-.28 * * *$ & $-.16^{* *}$ & $-.16^{*}$ & $-73.57 * * *$ & $-.20 * *$ & $-1.02 * * *$ & $.09 *$ \\
\hline Czech Republic & 1.2 & -3.14 & $1.50^{* * *}$ & -.02 & $1.48 * * *$ & $-.32 * * *$ & $-.17 * * *$ & -.06 & $-30.76^{* * *}$ & $-.15^{*}$ & -.15 & .06 \\
\hline Slovenia & 1.2 & -2.64 & $.96 * * *$ & -.03 & $.95 * * *$ & $-.29 * *$ & $-.17 * * *$ & $-.17 *$ & $-74.83^{* * *}$ & $-.18 * *$ & .10 & $.08 *$ \\
\hline Germany & 1.3 & -2.74 & $.86^{* * *}$ & -.01 & $.87 * * *$ & $-.45 * * *$ & $-.14^{*}$ & -.09 & $-1.04 * * *$ & $-.17^{*}$ & $-.62 * * *$ & $.11 *$ \\
\hline Greece & 1.3 & -4.95 & $3.02 * * *$ & -.01 & $2.73^{* * *}$ & $-.20+$ & $-.15^{*}$ & -.10 & $-1.76 * * *$ & $-.19 * * *$ & .01 & $.09+$ \\
\hline Austria & 1.4 & -2.90 & $1.20^{* * *}$ & -.08 & $.83 * * *$ & $-.46^{* * *}$ & $-.15^{* *}$ & -.09 & -.28 & $-.20 * * *$ & .06 & $.09+$ \\
\hline Slovakia & 1.4 & -3.94 & $2.28^{* * *}$ & .01 & $2.06^{* * *}$ & $-.28 * * *$ & $-.18^{*}$ & -.08 & $1.23 * * *$ & $-.21 * * *$ & $-.21^{*}$ & .05 \\
\hline Portugal & 1.5 & -3.01 & $1.14^{* * *}$ & -.01 & $1.07 * * *$ & $-.36^{* * *}$ & $-.17 * * *$ & -.02 & $-2.46^{* * *}$ & $-.23 * * *$ & $-.45^{* * *}$ & $.11^{* *}$ \\
\hline Netherlands & 1.5 & -3.16 & $1.35^{* * *}$ & -.09 & $1.25^{* * * *}$ & $-.40 * * *$ & $-.14^{*}$ & -.11 & $-61.96 * * *$ & $-.20 * * *$ & $-11.15^{* * *}$ & $.13^{* * *}$ \\
\hline Belgium & 1.5 & -2.72 & $1.11^{* * *}$ & -.01 & $.89^{* * *}$ & $-.32 * * *$ & $-.15^{*}$ & -.07 & $-1.54 * * *$ & $-.18 * * *$ & $-.32+$ & $.07+$ \\
\hline Sweden & 1.5 & -2.77 & $1.14^{* * *}$ & -.06 & $.93 * * *$ & $-.35 * * *$ & $-.16^{* *}$ & -.07 & $-.29+$ & $-.20 * * *$ & $-25.38 * * *$ & .07 \\
\hline France & 1.7 & -2.51 & $.96^{* * *}$ & -.03 & $.79 * * *$ & $-.37 * * *$ & $-.17 * * *$ & $-.13+$ & $-35.22 * * *$ & $-.17 * * *$ & $-1.39 * * *$ & $.09 *$ \\
\hline Great Britain & 1.7 & -1.80 & $.25^{* * *}$ & -.10 & $.28^{*}$ & $-.44 * * *$ & $-.19 * * *$ & -.11 & $-2.22 * * *$ & $-.26 * * *$ & $.43 *$ & $.09^{*}$ \\
\hline Denmark & 1.7 & -2.37 & $.65^{* * *}$ & -.17 & $.81 * * *$ & $-.33 * * *$ & $-.17 *$ & -.09 & $-.32+$ & $-.18 * *$ & $-.94 * * *$ & $.10^{*}$ \\
\hline Finland & 1.7 & -2.11 & $.68 * * *$ & -.09 & $.55^{* * *}$ & $-.26^{* *}$ & $-.16^{* *}$ & $-.11+$ & $-1.10 * * *$ & $-.20 * * *$ & $1.72 * * *$ & .08 \\
\hline Australia & 1.8 & -2.76 & $1.13^{* * *}$ & -.05 & $.99 * * *$ & $-.54 * * *$ & $-.18 * * *$ & -.16 & $-.66^{*}$ & $-.22 * * *$ & $-.55^{* * * *}$ & $.10^{* * *}$ \\
\hline Norway & 1.8 & -3.03 & $1.46^{* * * *}$ & -.08 & $1.12 * * *$ & $-.43^{* * *}$ & $-.17 * *$ & -.10 & $-.43+$ & $-.21 * * *$ & -.15 & $.08+$ \\
\hline Ireland & 1.9 & -2.29 & $.82 * * *$ & .01 & $.84 * * *$ & $-.38 * * *$ & $-.17 * *$ & $-.14+$ & -.05 & $-.23 * * *$ & $-1.11 * * *$ & $.10^{*}$ \\
\hline United States & 2.0 & -1.56 & .12 & .05 & $.25^{* *}$ & $-.38 * * *$ & $-.20 * * *$ & -.03 & $-.36^{*}$ & $-.23 * * *$ & $-.75^{* * *}$ & $.10^{*}$ \\
\hline
\end{tabular}




\section{$\underline{\text { References }}$}

Arnold, Fred, Rodolfo A. Bulatao, Chalio Buripakdi, Betty Jamie Chung, James T. Fawcett, Toshio Iritani, Sung Jin Lee, and Tsong-Shien Wu. 1975. The Value of Children. Honolulu, HI: East-West Institute.

Bagavos, Christos and Claude Martin. 2000. "Low Fertility, Families and Public Policies." Synthesis Report for the annual seminar of the European Observatory on Family Matters, September 15-16, Sevilla, Spain.

Baxter, Janeen and Emily Kane. 1995. "Dependence and Independence: A Cross-National Analysis of Gender Inequality and Gender Attitudes." Gender and Society 9 (2): 193-215.

Blossfeld, Hans Peter and Götz Rohwer. 1995. Techniques of Event History Modeling: New Approaches to Causal Analysis. Mahwah, NJ: Lawrence Erlbaum.

Bongaarts, John. 2002. "The End of the Fertility Transition in the Developed World." Population and Development Review 28 (3): 415-450.

Brewster, Karin L. and Ronald R. Rindfuss. 2000. "Fertility and Women's Employment in Industrialized Nations.” Annual Review of Sociology 26: 271-296.

Budig, Michelle J. 2003. "Are Women's Employment and Fertility Histories Interdependent? An Examination of Causal Order Using Event History Analysis." Social Science Research 32: $376-401$.

Caldwell, John, Patricia Caldwell, and Peter McDonald. 2002. "Policy Responses to Low Fertility and its Consequences: A Global Survey." Journal of Population Research 19 (1): 1-24.

Caldwell, John. 2001. "The Globalization of Fertility Behavior.” Pp. 93-115 in Global Fertility Transition edited by Rodolfo A. Bulatao and John B. Casterline. New York, NY: The Population Council.

Carlos, Monica P. and Laura Maratou-Alipranti. 2000. "Family Policy and New Family Forms: The Cases of Greece and Portugal." Pp. 34-48 in Families and Family Policies in Europe: Comparative Perspectives edited by Astrid Pfenning and Thomas Bahle. Frankfurt: Peter Lang $\mathrm{GmbH}$.

Chesnais, Jean-Claude. 1996. "Fertility, Family, and Social Policy in Contemporary Western Europe." Population and Development Review 22 (4): 729-739.

1998. "Below-Replacement Fertility in the European Union (EU-15): Facts and Policies, 1960-1997." Review of Population and Social Policy 7: 83-101. 
Cox, D.R. and D. Oates. 1984. Analysis of Survival Data. London: Chapman and Hall.

Ellingsaeter, Anne Lise. 2000. "Scandinavian Transformations: Labour Markets, Politics and Gender Divisions." Economic \& Industrial Democracy 21: 335-359.

Ermisch, John F. 2003. An Economic Analysis of the Family. Princeton, NJ: Princeton University Press.

Esping-Andersen, Gøsta. 1999. Social Foundations of Postindustrial Economies. New York, NY: Oxford University Press.

European Commission. 2002. "Employment in Europe 2002: Recent Trends and Prospects." European Commission for Employment and Social Affairs. Available online at: http://europa.eu.int/comm/employment_social/publications/2002/keah02001_en.pdf

Eydal, Gudny B. 2000. "Nordic Child-Care Policies and the Case of Iceland.” Pp. 104-126 in Families and Family Policies in Europe: Comparative Perspectives edited by Astrid Pfenning and Thomas Bahle. Frankfurt: Peter Lang GmbH.

Flaquer, Lluis. 2000. “Is There a Southern European Model of Family Policy?” Pp. 15-33 in Families and Family Policies in Europe: Comparative Perspectives edited by Astrid Pfenning and Thomas Bahle. Frankfurt: Peter Lang GmbH.

Frejka, Tomas and John Ross. 2001. "Paths to Subreplacement Fertility and the Empirical Evidence." Pp. 213-254 in Global Fertility Transition edited by Rodolfo A. Bulatao and John B. Casterline. New York: The Population Council.

Gammerman, Dani. 1997. Markov Chain Monte Carlo: Stochastic Simulation for Bayesian Inference. London: Chapman and Hall.

Gauthier, Ann and Jan Hatzius. 1997. "Family Benefits and Fertility: An Econometric Analysis." Population Studies 51: 295-306.

Gefland, Alan E. 1994. "Model Determination Using Sampling-Based Methods.” Pp.145-161 in Markov Chain Monte Carlo in Practice edited by W.R. Gilks, S. Richardson, and D. J. Spiegelhalter. Boca Raton, FL: Chapman and Hall.

Gelman, Andrew, John B. Carlin, Hal S. Stern, and Donald B. Rubin. 2004. Bayesian Data Analysis (second edition). Boca Raton, FL: Chapman and Hall.

Gilks, Walter R., Sylvia Richardson, and David J. Spiegelhalter. 1994. "Introducing Markov Chain Monte Carlo." Pp.1-19 in Markov Chain Monte Carlo in Practice edited by W.R. Gilks, S. Richardson, and D. J. Spiegelhalter. Boca Raton, FL: Chapman and Hall. 
Goldstein, Joshua, Wolfgang Lutz, and Maria Rita Testa. 2003. "The Emergence of Subreplacement Family Size Ideals in Europe.” Population Research and Policy Review 22: 479-496.

Gornick, Janet and Marcia Meyers. 2003. Families that Work: Policies for Reconciling Parenthood and Employment. New York, NY: Russell Sage Foundation.

Greve, Bent. 2000. "Family Policy in the Nordic Countries.” Pp. 181-199 in Families and Family Policies in Europe: Comparative Perspectives edited by Astrid Pfenning and Thomas Bahle. Frankfurt: Peter Lang GmbH.

Guerrina, Roberta. 2002. "Mothering in Europe: Feminist Critique of European Policies on Motherhood and Employment." The European Journal of Women's Studies 9 (1): 49-68.

Hakim, Catherine. 2003. "A New Approach to Explaining Fertility Patterns: Preference Theory." Population and Development Review 29 (3): 349-374.

Harkness, Susan and Jane Waldfogel. 1999. "The Family Gap in Pay: Evidence From Seven Industrialised Countries." Center for Analysis of Social Exclusion, CASEpaper 29. Available online at: http://sticerd.lse.ac.uk/dps/case/cp/CASEpaper30.pdf

Hoffman, David A. 1997. "An Overview of the Logic and Rationale of Hierarchical Linear Models." Journal of Management 23(6): 723-744.

Jones, Gavin W., Robert M. Douglas, John Caldwell, and Rennie D’Souza. 1997. The Continuing Demographic Transition. New York, NY: Oxford University Press.

Jones, Rachel and April Brayfield. 1997. "Life's Greatest Joy?: European Attitudes Toward the Centrality of Children." Social Forces 75 (4): 1239-1269.

Kalleberg, Arne L. 2000. "Non Standard Employment Relations: Part-Time, Temporary and Contract Work." Annual Review of Sociology 26: 341-365.

Kögel, Tomas. 2004. "Did the Association between Fertility and Female Employment Within OECD Countries Really Change its Sign?" Journal of Population Economics 17: 45-65.

Kohler, Hans-Peter, Francesco C. Billari, and Jose Antonio Ortega. 2002. "The Emergence of Lowest-Low Fertility in Europe during the 1990s." Population and Development Review 28 (4) 641-680.

Laaksonen, Helena. 2000. "The Welfare of Young Adults in Europe between Work, Family, and State." Pp. 340-354 in Families and Family Policies in Europe: Comparative Perspectives edited by Astrid Pfenning and Thomas Bahle. Frankfurt: Peter Lang GmbH. 
Lesthaeghe, Ronald. 1995. “The Second Demographic Transition in Western Countries: An Interpretation." Pp. 17-62 in Gender and Family Change in Industrialized Countries edited by Karen Oppenheim Mason and Ann-Magritt Jensen. Oxford: Oxford University Press.

Lewis, Jane. 2006. "Work/Family Reconciliation, Equal Opportunities, and Social Policies: The Interpretation of Policy Trajectories at the EU Level and the Meaning of Gender Equality." Journal of European Public Policy 13(3): 420-437.

Mandel, Hadas and Moshe Semyonov. 2006. "A Welfare State Paradox: State Interventions and Women's Employment Opportunities in 22 Countries.” American Journal of Sociology 111:1910-1949.

Mason, Karen Oppenheim. 1997. “Gender and Demographic Change: What Do We Know?” Pp. 158-182 in The Continuing Demographic Transition edited by Gavin W. Jones, Robert M. Douglas, John Caldwell, and Rennie D’Souza. New York, NY: Oxford University Press.

--------. 2001. “Gender and Family Systems in the Fertility Transition.” Pp.160-176 in Global Fertility Transition edited by Rodolfo A. Bulatao and John B. Casterline. New York, NY: The Population Council.

Mason, Karen Oppenheim and Karen Kuhlthau. 1992. "The Perceived Impact of Child Care Costs on Women's Labor Supply and Fertility.” Demography 29 (4): 523-543.

McDonald, Peter. 2000. "Gender Equity in Theories of Fertility Transition." Population and Development Review 26 (3): 427-439.

--------. 2000. "Gender Equity, Social Institutions, and the Future of Fertility." Journal of Population Research 17 (1): 1-16.

--------. 2001. "Work-Family Policies are the Right Approach to the Prevention of Very Low Fertility." People and Place 9 (3): 17-28.

-------. 2002. Low Fertility: Unifying the Theory and the Demography. Paper presented at the annual meeting of the Population Association of America, May 9-11, Atlanta, GA. Available online at: http://eprints.anu.edu.au/archive/00001113/

McNicoll, Geoffrey. 2001. "Government and Fertility in Transitional and Post-Transitional Societies." Pp. 129-159 in Global Fertility Transition edited by Rodolfo A. Bulatao and John B. Casterline. New York, NY: The Population Council.

Morgan, Kimberly J. and Kathrin Zippel. 2003. "Paid to Care: The Origins and Effects of Care Leave Policies in Western Europe.” Social Politics 10(1): 49-85. 
Neyer, Gerda. 2003. "Family Policies and Low Fertility in Western Europe.” Working paper for the Max Planck Institute of Demographic Research. Available online at: http://www.demogr.mpg.de/papers/working/wp-2003-021.pdf

Organization for Economic Cooperation and Development. 2002. "Women at Work: Who Are They and How Are They Faring?" Organization for Economic Cooperation and Development Employment Outlook. Available online at: http://www.oecd.org/dataoecd/36/7/17652667.pdf

Organization for Economic Cooperation and Development. 2001. "Balancing Work and Family Life: Helping Parents Into Paid Employment." Organization for Economic Cooperation and Development Employment Outlook. Available online at: http://www.oecd.org/dataoecd/11/12/2079435.pdf

Orloff, Ann. 1996. “Gender in the Welfare State.” Annual Review of Sociology 22: 51-79.

Pinnelli, Antonella. 1995. "Women's Condition, Low Fertility, and Emerging Union Patterns in Europe.” Pp. 82-101 in Gender and Family Change in Industrialized Countries edited by Karen Oppenheim Mason and Ann-Magritt Jensen. Oxford: Oxford University Press.

Presser, Harriet B. 2001. "Comment: A Gender Perspective for Understanding Low Fertility in Post-Transitional Societies." Pp. 177-183 in Global Fertility Transition edited by Rodolfo A. Bulatao and John B. Casterline. New York, NY: The Population Council.

Raudenbush, Stephen and Anthony S. Bryk. 2002. Hierarchical Linear Models: Applications and Data Analysis Methods, Second Edition. Thousand Oaks, CA: Sage Publications.

Rindfuss, Ronald R., Karen Benjamin Guzzo, and S. Philip Morgan. 2003. "The Changing Institutional Context of Low Fertility." Population Research and Policy Review 22: 411438.

Robert, Christian P. 1994. The Bayesian Choice: A Decision-Theoretic Motivation. New York, NY: Springer.

Rowland, Donald T. 2007. "Historical Trends in Childlessness." Journal of Family Issues 28 (10): 1311-1337.

Sleebos, Jöelle. 2003. "Low Fertility Rates in OECD Countries: Facts and Policy Responses." Organisation for Economic Co-operation and Development. Available online at: http://www.oecd.org/dataoecd/13/38/16587241.pdf

Sundström, Eva. 2000. "Gender Attitudes Toward Female Employment in Germany, Italy, and Sweden." Pp. 200-220 in Families and Family Policies in Europe: Comparative Perspectives edited by Astrid Pfenning and Thomas Bahle. Frankfurt: Peter Lang GmbH. 
Tsui, Amy O. 2001. "Population Policies, Family Planning Programs, and Fertility: The Record." Pp. 184-204 in Global Fertility Transition edited by Rodolfo A. Bulatao and John B. Casterline. New York, NY: The Population Council.

Tsuya, Noriko and Karen Oppenheim Mason. 1995. "Changing Gender Roles and BelowReplacement Fertility in Japan." Pp. 139-167 in Gender and Family Change in Industrialized Countries edited by Karen Oppenheim Mason and Ann-Magritt Jensen. Oxford: Oxford University Press.

Waldfogel, Jane. 1998. "Understanding the 'Family Gap' in Pay for Women with Children." The Journal of Economic Perspectives 12 (1): 137-156.

Wang, Weiren and Felix Famoye. 1997. "Modeling Household Fertility Decisions with Generalized Poisson Regression." Journal of Population Economics 10: 273-283.

Weiss, Doris. 2000. “The European Union and the Family: Law and Policy.” Pp. 127-140 in Families and Family Policies in Europe: Comparative Perspectives edited by Astrid Pfenning and Thomas Bahle. Frankfurt: Peter Lang GmbH.

Zelizer, Viviana A. 1985. Pricing the Priceless Child: The Changing Social Value of Children. Princeton, NJ: Princeton University Press. 